\title{
Affordable Housing Retrofitting Strategies through Coupling Simulation Method Criteria
}

\author{
Y. Magdy ${ }^{1}$, W. Kamel' ${ }^{2}$ A. El Menshawy ${ }^{1}$
}

\begin{abstract}
Nowadays many of social housing in Alexandria are often obsolete with inadequate condition that represent through the comfort conditions, energy consumption and structural conditions moreover the lack of the minimum aspects of the architectural aesthetic elements. over $50 \%$ of the Egyptian population live in informal settlement. Alexandria has a great share of these slums, while it contains more than 36 informal setlements. The residential sector consume about $47 \%$ of all the electricity consumption. The government constructing a large concrete blocks without concerning about the environmental issues during the decision making or design buildings more energy efficient. Also this buildings with old energy technologies affects the overall energy consumption in the city. this research aims to state the significance of choosing the appropriate software in decision making for retrofitting strategies of building energy and micro climate simulation through formulating a strategic framework of concentration area, selection and assessment criteria applied of different architect friendly softwares, concluding by applying the passive design strategies reaching the most effictive thermal comfort techniques through coupling method in order to simulate the building energy and micro climate by eQuest which employs DOE-2.2 and Designbuilder which employs Energyplus along with the micro-climate tools such as CityBES and ENVI-met respectively as the most architect friendly use softwares.
\end{abstract}

KEYWORDS: informal settlements, microclimate simulation, energy simulaiton, retrofitting systems, passive systems

\section{INTRODUCTION}

Informal settlements were described through a numerous varied definitions, and each of them was based on some of the characteristics that characterize slums, in terms of being illegal, unplanned and marginal areas. Recently the slums were frequently mentioned as it is a global concern to reflect the depth of this phenomenon in its housing and population dimensions.

Slum areas are described as areas that constructed by self-efforts, they are built in the absence of law in settlements which have not been planned. That can be environmentally and socially insecure which is characterized by a low level of basic services and lack of facilities. Resulted in a segment of society whose values and principles are decreasing in the face of the overwhelming need for food, housing, clothing and sense of security [1]. Over 50\% of the population in Egypt lives in informal areas [2]. Alexandria has a great share of the informal settlements as over two third of the population lives in slums distributed through all the city districts as shown in table 1 [3].

\footnotetext{
${ }^{1}$ Architecture Engineering and Environmental Design Department, College of Engineering and Technology, Arab Academy for Science, Technology and Maritime Transport, Alexandria, Egypt.

${ }^{2}$ Construction and Building Engineering Department, College of Engineering and Technology, Arab Academy for Science, Technology and Maritime Transport, Alexandria, Egypt.
} 
The annual demand for residential units in Egypt ranges between 200 thousand to 300 thousand housing units, to meet the needs of population growth and internal migration, the government housing sector providing $27.4 \%$ of this requirement. The private sector also provides the same rate of $27.4 \%$, while random housing fills $45.2 \%$ of this requirement, making the largest reliance on the need to meet the need for random housing [3].

Table 1. Informal settlements distribution in Alexandria [3]

\begin{tabular}{|c|c|c|c|c|c|}
\hline $\begin{array}{c}\text { Name of the } \\
\text { District }\end{array}$ & $\begin{array}{l}\text { Size in } \\
\mathrm{Km}^{2}\end{array}$ & Total population/year & $\begin{array}{c}\text { Number of } \\
\text { informal areas }\end{array}$ & $\begin{array}{l}\text { Average Density } \\
\mathrm{P} / \mathrm{Km}^{2}\end{array}$ & $\begin{array}{l}\text { Safe / } \\
\text { unsafe }\end{array}$ \\
\hline El Montaza & 82 & $1,585,572 / 2018$ & 9 & 19,336 & Safe \\
\hline Sharek (East) & 35 & $1,158,822 / 2018$ & 5 & 33,109 & Safe \\
\hline Wasat (Middle) & 68 & $543,405 / 2018$ & 2 & 7,991 & Safe \\
\hline El Gomerk & 4.7 & $156,780 / 2018$ & 2 & 33,357 & Safe \\
\hline Gharb (West) & 20.1 & $356,613 / 2018$ & 8 & 17,741 & unsafe \\
\hline Sub Total & 209.8 & $2,801,192$ & 26 & 13,351 & \\
\hline $\begin{array}{l}\text { El Amriya+ } \\
\text { El Agamy }\end{array}$ & 1555.5 & $\begin{array}{c}617,384+ \\
608,674 / 2018\end{array}$ & $\begin{array}{c}5+ \\
4\end{array}$ & 788 & $\begin{array}{l}\text { Safe + } \\
\text { unsafe }\end{array}$ \\
\hline Borg El Arab & 534.7 & $133,543 / 2018$ & 1 & 250 & Safe \\
\hline Total & 2300 & $5,225,979 / 2019$ & 36 & 2,272 & \\
\hline
\end{tabular}

\subsection{Problem Statement}

By 2014 Egypt has a total electricity capacity of 174.9 Billion $\mathrm{kWh}$, all the distributed amount is 146.6 Billion $\mathrm{kWh}$, the residential sector consume 63.5 Billion $\mathrm{kWh}$ compared to 2018 the residential sector consume 83.4 Billion $\mathrm{kWh}$ with increasing ratio $7.6 \%$. The total electricity of residential houses increases from $36.6 \%$ to $42.4 \%$ with loss of $7.7 \%$ of generated energy and $3.2 \%$ self-consumption by the station, with a total up to $53.3 \%$. However the government implementing new electricity generation stations through renewable and non-renewable sources that only the whole consumption payback covers $63 \%$ of total cost while increasing the cost by average $30 \%$ between $2019-2020$ in order to cut all the governmental financial support by 2025 .

The problem is the increasing gap between the energy consumption and energy production due to the new urban communities.

\subsection{Research aim and objectives}

This research aims to the significance of choosing appropriate software in decision making for retrofitting strategies of the building energy and micro climate simulation considering the occupants' thermal comfort for the new residential complex determining the appropriate simulation software testing the retrofitting system, through the following objectives:

- Determining the meteorological parameters affecting the occupants' thermal comfort.

- Considering the retrofitting strategies of building and micro-climate.

- Applying the energy simulation through different software by a concentration areas, selection and assessment criteria.

- Determining the architect friendly software.

\section{The Meteorological Parameters Affecting The Occupants' Thermal Comfort}

The need to achieve a good indoor environmental quality (IEQ) as a result of thermal, visual, acoustic comfort and indoor air quality. The awareness increased that an adequate design of the indoor environment, where people work and live, requires a synergic approach to all facets involved in full compliance with sustainability. IEQ strictly affects the overall building energy performances and exhibits an antagonistic relationship with respect to the energy saving requirements [4]. 
Thermal comfort is defined by the opinion of people who occupy a space, depending on the subjective feeling related to temperature, it refers to the perception of occupants, and should be modified as possible to avoid situations of discomfort or thermal stress. Thermal comfort must be guaranteed as a neutral condition, thermal comfort described through seven points thermal sensation scale between the Predicted Mean Vote (PMV) and Occupants' sensation as shown in Table 2 [5].

Table 2. The 7-point thermal sensation scale [5]

\begin{tabular}{|r|r|r|r|r|r|r|r|}
\hline PMV vote & $\mathbf{+ 3}$ & $\mathbf{+ 2}$ & $\mathbf{+ 1}$ & $\mathbf{0}$ & $\mathbf{- 1}$ & $\mathbf{- 2}$ & $\mathbf{- 3}$ \\
\hline Sensation & Hot & Warm & $\begin{array}{r}\text { Slightly } \\
\text { warm }\end{array}$ & Neutral & $\begin{array}{r}\text { Slightly } \\
\text { cool }\end{array}$ & Cool & Cold \\
\hline
\end{tabular}

Physiological equivalent temperature (PET), where the exchange between human body and environment is evaluated and, in relation to the different equilibrium situations, is defined as a perceived equivalent temperature by a subject, PMV and Percentage People Dissatisfied (PPD\%), which is related to the felling and judgment of people as shown in Fig.1 [5].

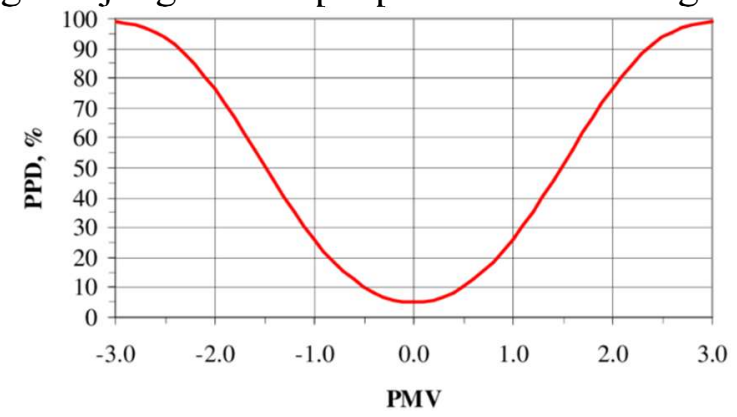

Fig. 1 Thermal sensation scale [5]

Physical parameters of indoor environment is related to the air volume enclosed in the building, this is an open system that:

- Exchanges mass, because of the air passage through doors and windows, and air leakage, which causes as well the movement of indoor pollutants, such as dust and $\mathrm{CO}_{2}$,

- Exchange energy, because of the difference in temperature between indoor and outdoor spaces, because of heating due to the sun or to the presence of people, or to the variation in latent heat due to absolute, specific and relative humidity as shown in Table 3 [6].

Table 3. The variables influencing the indoor environment [6]

\begin{tabular}{|c|c|c|c|c|c|}
\hline & \multicolumn{5}{|c|}{ The variables influencing indoor environment } \\
$\begin{array}{c}\text { Air temperature, } \\
\text { measured in }{ }^{\circ} \mathrm{C}\end{array}$ & $\begin{array}{c}\text { Mean radiant } \\
\text { temperature } \\
\text { (MRT) } \\
\text { measured in }{ }^{\circ} \mathrm{C}\end{array}$ & $\begin{array}{c}\text { Absolute } \\
\text { humidity, } \\
\text { measure in } \\
\mathrm{gv} / \mathrm{m}^{3}\end{array}$ & $\begin{array}{c}\text { Specific } \\
\text { Humidity } \\
\text { measured in } \\
\text { gv/kga }\end{array}$ & $\begin{array}{c}\text { Relative } \\
\text { humidity (RH), } \\
\text { measured in } \\
\text { percentage (\%) }\end{array}$ & $\begin{array}{c}\text { Air velocity (v), } \\
\text { measured in m/s }\end{array}$
\end{tabular}

\section{STRATEGIES FOR ENERGY RETROFITTING}

The design that maintains a comfortable temperature within the building using the climate and natural elements to get the optimum benefit and to reduce or eliminate the independence on mechanical systems for heating, cooling and lighting, is called 'Passive Design'. There are two crucial measures for passive design to be beneficial and effective: climate and comfort. To get the maximum benefit of energy retrofitting for a building it's needed to combine different strategies [7].

Analytical considerations to Design an Energy efficient Building in order to get the optimum benefit of the retrofitting strategy, needs to consider the following:

\section{A. Building orientation}

Building orientation governs the passive technologies implementation within the design. It also governs the window sizing and locations, which will affect both lighting space conditioning within a 
building. Proper orientation can lead to significant reduction in lighting and space conditioning load if coupled with passive design technologies [8].

\section{B. Building shape}

Well-designed passive building produces less air pollution and greenhouse gasses, and thus it contributes to a more sustainable environment. Good passive buildings not only conserve energy, but also account for hidden environmental benefits. Massing of the building blocks help achieve thermal and visual comfort. Building blocks channelize or obstruct the wind flow, also act as shading devices for surroundings. Building blocks design and geometry can influence the wind flow and velocity [9].

\section{Material selection}

Choice of material depends on the outside climate around the building. However, the properties of material used, which governs their usage, can be noted as three different properties. Color, insulation property and assembly type. Finishes color will vary the amount of heat and light absorbed and reflected. Lighter the color greater reflectivity while darker the color more absorbing property. In addition, the insulation property plays an important role in material selection. Good insulation is required to reduce heat exchange between the internal and external space [10].

\section{MICRO-CLIMATE LEVELS}

Many urban and suburban areas experience elevated temperatures compared to their outlying rural surroundings, this difference in temperature is what constitutes an urban heat island (UHI) [11].

According to the characterization in different layers of urban heat island is divided into three categories surface urban heat island (SUHI), canopy urban heat island (CUHI) and boundary urban heat island (BUHI), The BUHI is relatively hard to detect due to temperature difference from sensors mounted on tall towers, balloons and aircraft and climate model simulation has been usually used to understand the characterization of BUHI. Canopy urban heat island is usually quantified by air temperature records from urban and rural stations The heterogeneous time series of air temperature records usually result in uncertainties of warming trend induced by urbanization process, Satellitebased land surface temperature (LST) is widely used in the monitoring of SUHI and can provide detailed information in regards to surface temperature variation over various land cover types as shown in Fig. 2 [12].

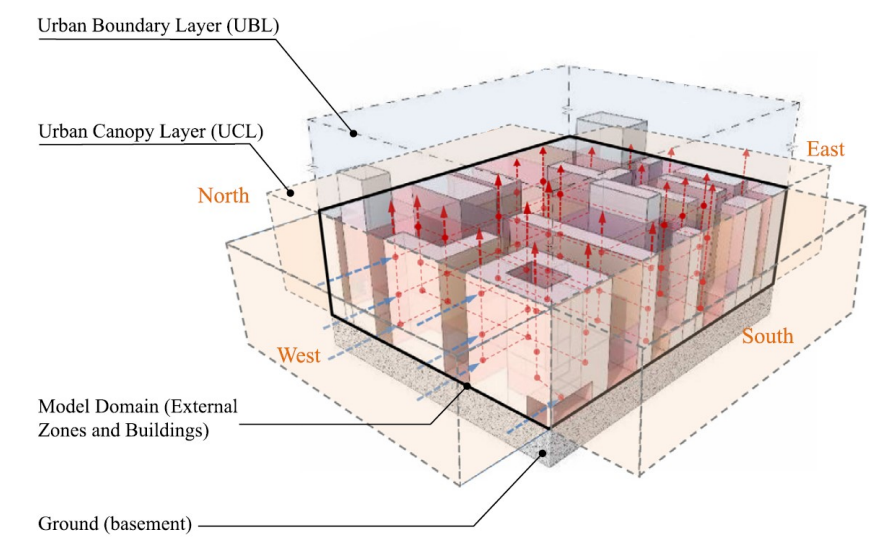

Fig.2 Schematic depiction of the urban microclimate levels [12]

Elevated temperatures from urban heat islands, particularly during the summer, can affect a community's environment and quality of life. Most impacts are negative and include:

- Increased energy consumption

- Elevated emissions of air pollutants and greenhouse gases

- Compromised human health and comfort 
In order to set a strategic criteria to control urban heat island in micro scale for energy consumption reduction needs the following:

1. Providing green spaces and vegetation in different layers of buildings

2. Using albedo materials on external surfaces of buildings

3. Providing void decks at ground level or at mid-span, variation of building height and arrangement of openings in building to face the prevailing wind can create natural ventilation.

4. Providing appropriate orientation of building and site for preventing sun radiation, encouraging air movement and natural ventilation.

\section{BUILDING INFORMATION MODELING}

A limited number of building energy simulation tools are integrated with building information modeling (BIM) through Industry Foundation Class (IFC) and Green Building XML (gbXML), additional efforts such as manual model check and modification for defining thermal zones are requested to generate reliable energy models. Simulation results into the design decision is still considered difficult. Typically, energy simulation tools provide a large quantity of numerical results presented in tables or charts [13].

Existing building energy simulation tools aim to evaluate energy performance and thermal comfort during a building's life cycle. Specifically, DOE-2 and EnergyPlus have been widely used at multiple stages of a building's life cycle due to their functionality of exchanging data with other tools through standard data formats as described in the "Building Energy Software Tools Directory"

The research surveyed more than two hundred software about evaluation of the performance of each tool in different categories such as graphical representation of results, easy learnability, short learning curve, flexibility of use and navigation, simple input options, flexible data storage, providing online support and training courses, providing weather data within the tool, and interoperability.

\subsection{Selection Criteria for Energy Simulation Softwares}

Developed criteria for assessing the architect-friendliness of the building information modeling (BEM) tools, this evaluation criteria consisted of five concentration areas as shown in table 4 [13].

Table 4 five concentration areas for evaluation criteria of the BEM tools 「13]

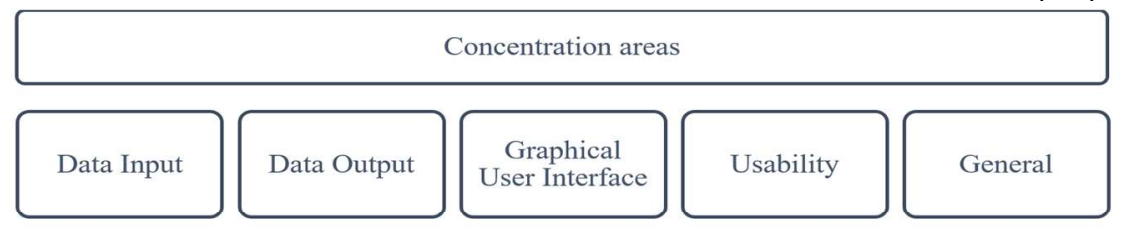

The first part focused on achieving quick and straight forward data input, as well as graphical representation of the geometry, while the second part focused on the interpretation of output results and the capabilities of parametric analysis. The third section stressed the importance of the Graphical User Interface (GUI) through clear and flexible navigation instead of using command line interface (CIL), the fourth section incorporated the usability for minimal and quick feedback, and a general section based on the overview of most commonly used BEM tools and the different developed selection criteria as shown in table 5 [14].

Table 5 Selection criteria for BEM tools [14]

\begin{tabular}{|c|c|c|c|c|}
\hline \multicolumn{5}{|c|}{ Selection criteria } \\
\hline $\begin{array}{l}\text { Usability and } \\
\text { Information } \\
\text { Management } \\
\text { of Interface }\end{array}$ & $\begin{array}{l}\text { Integration of } \\
\text { Intelligent } \\
\text { Design } \\
\text { Knowledge } \\
\text { base }\end{array}$ & $\begin{array}{l}\text { tools and the } \\
\text { ability to } \\
\text { simulate } \\
\text { detailed and } \\
\text { complex } \\
\text { building } \\
\text { components }\end{array}$ & $\begin{array}{l}\text { Interoperability } \\
\text { of building } \\
\text { modelling }\end{array}$ & $\begin{array}{l}\text { Integration } \\
\text { with } \\
\text { building } \\
\text { design } \\
\text { process. }\end{array}$ \\
\hline
\end{tabular}


The selected BEM tools for this research have higher penetration within the architectural practice, in addition to their integration with BIM tools. Also, defined the following assessment criteria from as shown in table 6 [15].

Table 6 Assessment criteria for BEM tools [15]

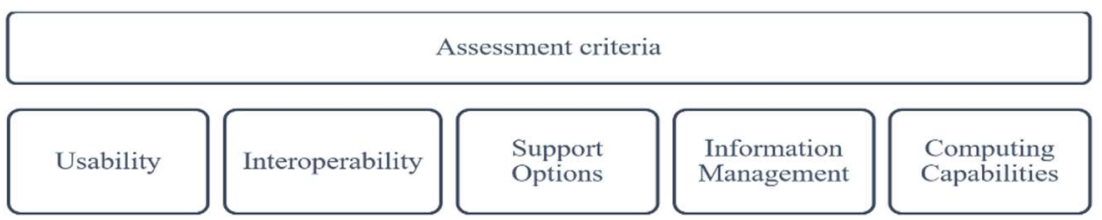

\subsection{User friendly energy Softwares for architects}

These software helping choose the most applicable software to be used by architects, depends on the software source availability, and the results validation. Using more than one software covering the microclimate simulation and building energy simulation combined together to give a holistic overview of energy performance. Emphasizing on test and assess the performance of the most commonly used BEM tools, by applying the previous criteria for (concentration areas, selection criteria, and assessment criteria) as shown in table 7.

Table 7 User friendly software for building energy simulation. Source: the researcher

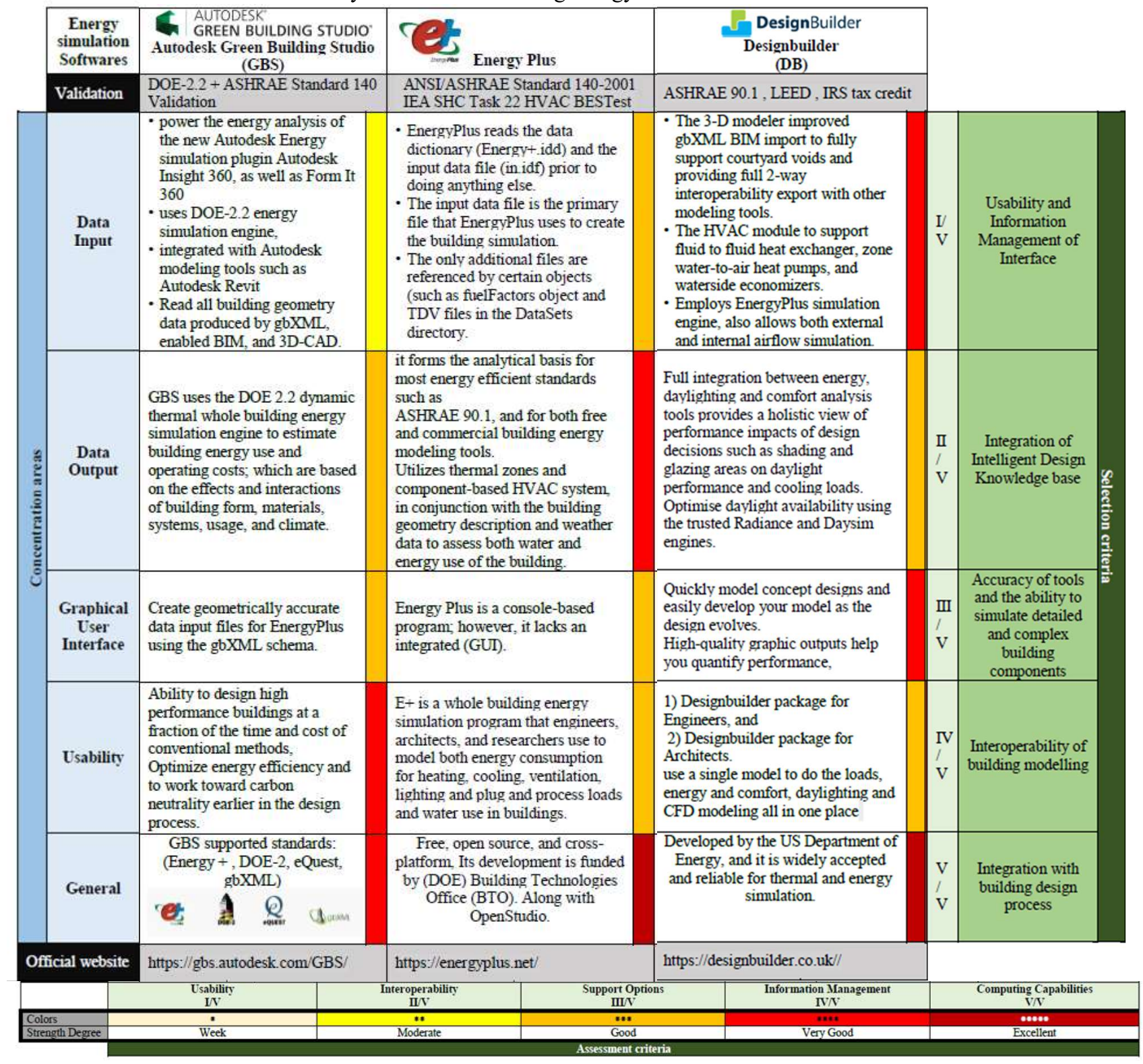


The US department of energy formerly hosted over two hundred energy simulation tools, the previous table 7 shows the user friendly software for building energy simulation, also there are more software like eQuest, Autodesk Insight Solar, Indoor Climate and Energy, and more selected according to the previous criteria. Reliably generating high quality BEM using current tools remains difficult. Although much of the process has been automated, intervention by the user to simplify models, choose among representations with subtle differences, and correct errors. Also there are software dedicated for the micro-climate simulation as shown in table 8.

Table 8 User friendly software for Micro-cliamte simulation. Source: the researcher

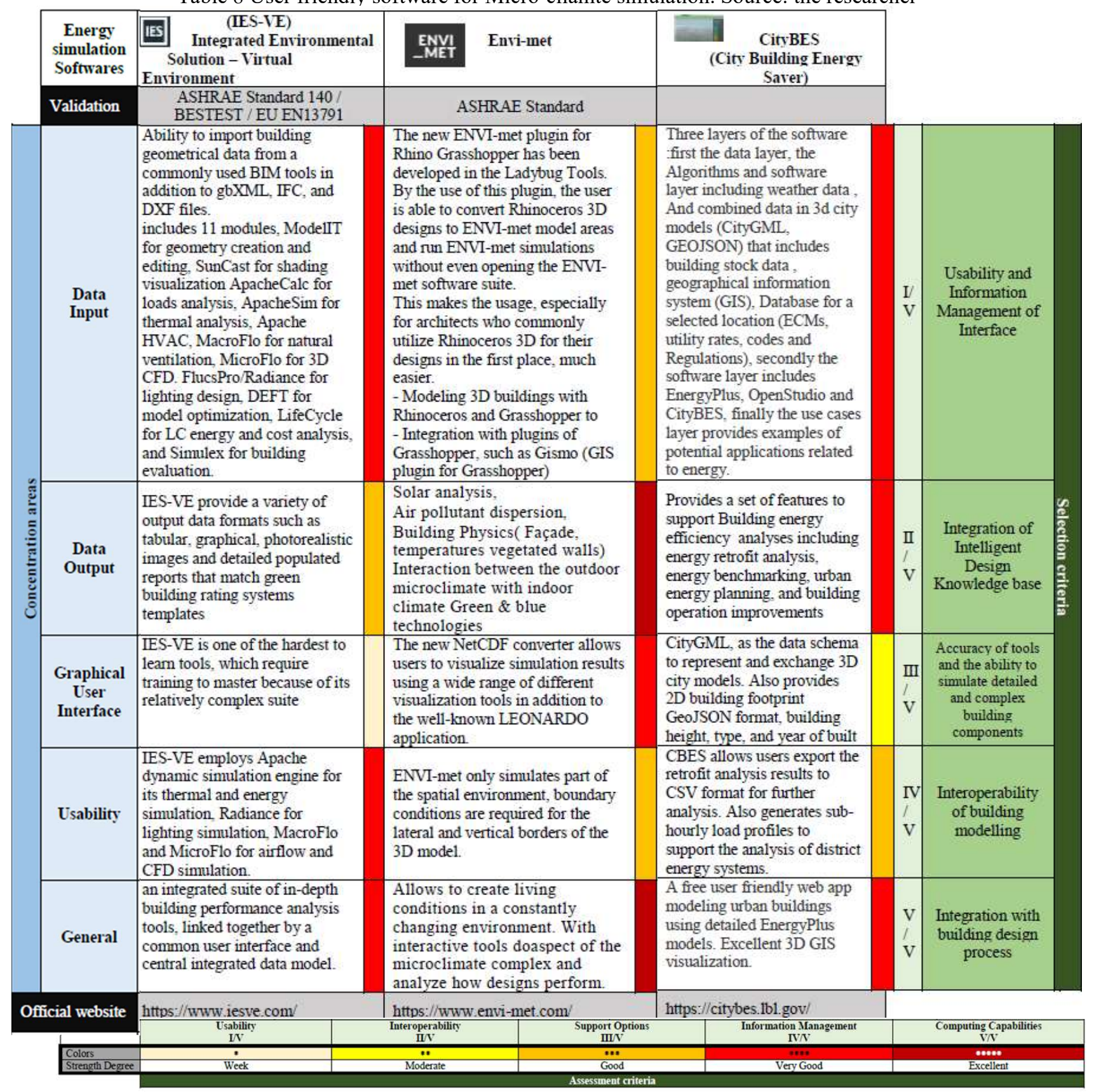

\section{CONCLUSION}

Energy efficient buildings aim to reduce the overall energy consumption necessary for their operation. High-performance buildings are designed to improve the overall building performance, besides energy usage, such as improving occupants' thermal, visual and acoustic comfort. Quantifiable 
predictions can help in identifying strategies and methods to improve building energy efficiency and the overall building performance.

Passive design is about taking advantage of natural energy flows to maintain thermal comfort. Passive technologies are systems which rely on natural resources and help to achieve comfort levels without relying on artificial energy. Choice of passive design techniques is majorly dependent on local climate where the project is located. The techniques are sustainable and use abundantly available natural resources. Integration of such techniques help transform building envelops into living organic creations to sustain human life within.

Urban heat islands refer to the elevated temperatures in developed areas compared to more rural surroundings. UHI are caused by development and the changes in radiative and thermal properties of urban infrastructure as well as the impact buildings can have on the local micro-climate.

\section{RECOMMENDATIONS}

In order to test the retrofitting systems to reach the most energy efficient scenarios required to use the coupling simulation method by combining the results from the building energy simulation and microclimate simulation based on the selection, assessment criteria and concentration areas in order to choose the most appropriate simulation software providing the relatively most accurate results for the occupants' thermal comfort through passive design strategies by using eQuest which employs DOE2.2 and Designbuilder which employs Energyplus along with the micro-climate tools such as CityBES and ENVI-met respectively as the most architect friendly use software.

\section{REFERENCES}

1. Ali, A. (2010). Reconsidering the problem of slums in light of the housing crisis. Cairo, Egypt: Partners in development for research, consulting and training.

2. Madbouly, M. (2016). Third united nations conference on housing and sustainable urban development (HABITAT 111). Cairo, Egypt : Minister of Housing, Utilities and Urban Communities.

3. ISDMC. (2019). Informal Residential Areas in Alexandria City, Information and Supporting Decision Makers Centre. Alexandria, Egypt: Alexandria Governorate.

4. Mujeebu, M. A. (2018). Indoor Environmental Quality. Department of Building Engineering, College of Architecture and Planning, Imam Abdulrahman Bin Faisal University, Dammam, Saudi Arabia.

5. Fanger, P. O. (1970). Thermal comfort-analysis and applications in environmental engineering. Copenhagen: Danish Technical Press.

6. Attia, S. (2006, April 16th). thermal comfort. Retrieved from Bioclimatic Design: http://www.shadyattia.net/academic/BioclimaticDesign/Lecture\%2001.html

7. Shen, P. (2019). The feasibility and importance of considering climate change impacts in building retrofit analysis. In Applied Energy. Cranfield, Bedford, United Kingdom.

8. Aksoy, T. (2006). Impacts of some building passive design parameters on heating demand for a cold region. Pretoria, South Africa: Elsevier Ltd., The Boulevard, Langford Lane, Kidlington, Oxford OX5 1GB, U.K.

9. Pedata, 1. (2011). Bioclimatic Principles Module. Rome, Italy: European Institute for Design. Retrieved from http://www.laurapedata.com/2010/04/01/environmental-design_ied-master/

10. Altan, H. (2016). Toward the Delivery of Zero Energy Mass Custom Homes. Switzerland: Springer International Publishing.

11. Khalizah, S. (2012). Modification of urban temperature in hot-humid climate through landscape design approach. MARA, Malaysia: Elsevier Ltd.

12. Hua, Y. (2019). Comparison of surface and canopy urban heat islands within megacities of eastern China. china: International Society for Photogrammetry and Remote Sensing, Inc. (ISPRS). Published by Elsevier B.V.

13. Attia, S. (2012). Simulation-based decision support tool for early stages of zero-energy building design Energy and Buildings.

14. Weytjens, L. (2010). The "Architect-friendliness" Of Six Building Performance Simulation Tools: A comparative Study. International Journal of Sustainable Building Technology and Urban Development, 237-344.

15. Issa, m. A. (2018). Building Performance Simulation For Architects, Comparing Three Leading Simulation Tools. Texas, united states of america : proquest llc. 


\section{SJCA الاورية العلمية لكلية القنون الجميلة - جامعة الإسكندرية

\section{استراتيجيات التعديل التحديثي للإسكان بأسعار معقولة من خلال معايير

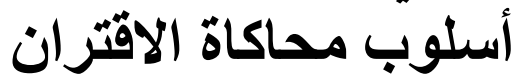

يوساب مجدى1، و وائل كامل2 ، عادل المنشاوى1

الملخص

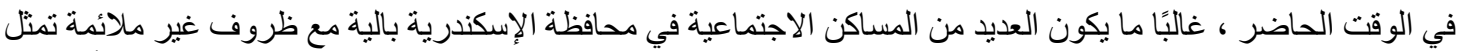

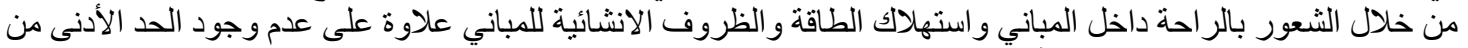

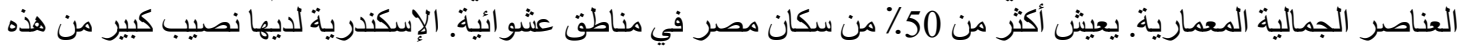

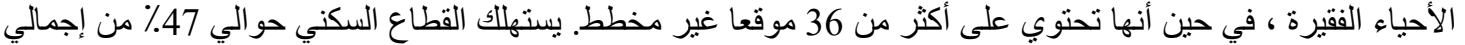

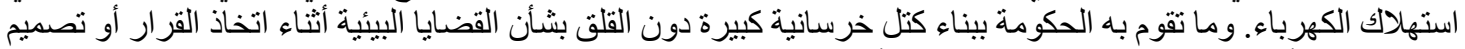

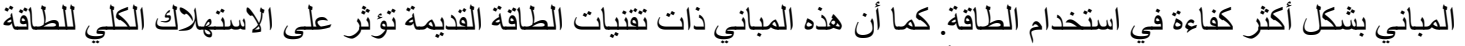

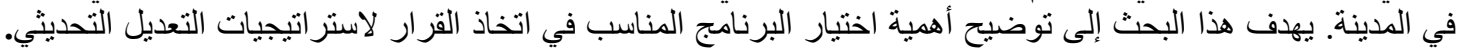

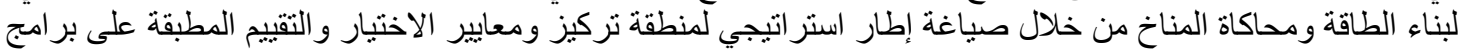

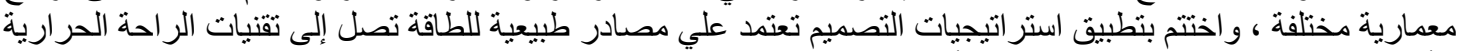

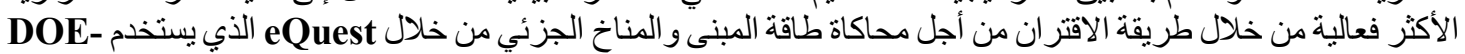
2.2 و Designbuilder الذي بستخدم Energyplus مع أدوات المناخ مثل CityBES و ومن البحث تعتبر هذه أكثر بر امج للاستخدام المعماري.

1 قسم الهندسة المعمارية و التصميم البيئي، كلية الهندسة والتكنولوجيا، الأكاديمية العربية للعلوم و التكنولوجيا و النقل البحري، الإسكندرية، مصر. yousabmagdy94@gmail.com. 2 قسم هندسة التشييد والبناء، كلية الهندسة والتكنولوجيا، الأكاديمية العربية للعلوم والتكنولوجيا و النقل البحري، الإسكندرية، مصر 